\title{
PREDICTION OF GENDER EMPLOYING MANDIBULAR MEASUREMENTS: APPLICATION OF CONE BEAM COMPUTERIZED TOMOGRAPHY
}

\author{
Abo Elyazied A. Fouad, ${ }^{1 ; 2} *$ Hussein I. Saudi ${ }^{3}$, Shereen Abdel Moula ${ }^{3}$, Mohamed Bayome ${ }^{4,5}$ \\ ${ }^{1}$ Department of Forensic Medicine and Clinical Toxicology, Faculty of Medicine, Tanta \\ University, Tanta, Egypt. \\ ${ }^{2}$ Division of Forensic Medicine,Department of Biomedical Science, College of Medicine, King \\ Faisal University, Al-Ahsa, Saudi Arabia. \\ ${ }^{3}$ Department of Oral Medicine, Periodontology, Diagnosis and Radiology, Faculty of Dentistry, \\ Tanta University. \\ ${ }^{4}$ Department of Preventive Dentistry, College of Dentistry, King Faisal University, Al-Ahsa, \\ Saudi Arabia. \\ ${ }^{5}$ Departamento de Estudios de Postgrado, Universidad Autónoma del Paraguay,Asuncian, Paraguay.

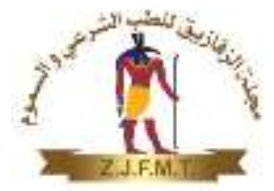

Corresponding author:

Abo Elyazied A. Fouad MD,*

E-mail address: draboyazid@yahoo.com

Phone: +966580349754

\section{ABSTRACT}

The identification of skeletal remains is of fundamental value in medico-legal fields. The skeletal components most often investigated for gender determination are the pelvis and skull, with the mandible especially in cases of destroyed bodies. The purpose of this study was to define the validity of mandibular measures taken through cone beam computerized tomography in sex determination and to establish a formula for such differentiation. The sample consisted of 100 Cone beam computerized tomography (CBCT). The CBCT images were analyzed for five measurements: the distance from the inferior border of the mandibular body to the highest point of the alveolar crest ( IBM-HAC), the distance between the inferior margins of the mental foramen to the inferior border of mandibular body (IMMF-IBM), the distance between the superior margins of the mental foramen to the highest point of the alveolar crest (SMMF-HAC), the distance between the superior margins of the mental foramen to the inferior border of the mandible (SMMFIBM), and volume of mental foramen. (VMF). Data analysis was achieved using SPSS version 22. Forward stepwise binary logistic regression analysis was accomplished to predict the probability of identifying male based on one or more independent variables. The logistic regression for the different varies revealed only the distance between the superior margins of the mental foramen to the inferior border of the mandible (SMMFIBM), and volume of mental foramen. (VMF) as the significant contributors to the regression model. The logistic regression model was statistically significant and able to $75 \%$ of the difference in sex and accurately categorized all cases. Based on the logistic regression model, an equation for prediction of sex was derived. In conclusion, the current study demonstrates the probability of sex determination employing mandibular measurements taken thought CBCT that is proved as a superior tool if compared with the other radiological techniques.

Key Words: Forensic Odontology, Mandible, Gender, Mental forame

\section{I- INTRODUCTION}

T he distinction in racial groups by analyzing the morphological features of the skeleton is a fundamental aspect in the scope of forensic anthropology (Thiago et al., 2016). Prediction of sex is an important parameters that may employ for precursory identification of missing persons (Annamalai et al., 2012 and Akhilesh et al., 2013). Because of the indestructible characters of craniofacial bones, a high definitive information can be obtained from such nondestroyed skeletal parts, including the mandible (Franklin et al., 2008).
As a role, the anthropologists use the morphological characters of the mandible in the determination of sex. Inclusion of mandibular radiographs as a part of the investigations will increase the accuracy of measurements (Humphrey et al., 1999). The digital panoramic technique may improve the quality of the radiograph with more obtained measurements' accuracy (Cagri et al., 2011).

Worldwide, the morphologic and morphometric sexual dimorphism of the mandible has been investigated in many studies in the United States, China, Japan, and Europe, for so, it is of great significance to link a particular population with their existing 
skeletal characters (Naroor et al., 2015). Mental foramen is the opening of mandibular canal in the body of mandible. It is fairly well depicted in panoramic radiographs that may show vertical and horizontal difference of location in different racial sets (Wei et al., 2010).

Computed tomography (CT), as a three-dimensional radiographic imaging technique, has been reported to be an effective tool for imaging head and neck structures both clinically as well as in forensic purposes (Rashid and Ali, 2011). Cone-beam computed tomography (CBCT), a more latterly applied variance of $\mathrm{CT}$, has shown various advantages if compared with the panoramic radiography and the conventional CT methods, including improvement of images adequacy, better uniformly resolution of the osseous structures with the expected improvement of findings' interpretations (Lubis and Anfelia 2018). The aim of this study was to focus light at the sexual dimorphism that may be exist between the male and the female gender using anthropometric mandibular measures on Cone beam computerized tomography images, and to set up a formula with prospect predictive estimates.

\section{II- PATIENTS AND METHODS}

This work was conducted on one hundred Cone beam computerized tomography images of 100 Saudi Arabia patients (54 males and 46 females), their ages ranged from 20-55 years. They were attending at four private dental care academies in the Eastern Provence, Saudi Arabia from the period from January 2017 to Jun 2018. The patients underwent a dental Cone beam computerized tomography examination as a part of their treatment. The approval of the local ethics committee of our institute was obtained after fulfillment of the ethical aspect. Written informed consent was gained from each patient for using his/ her personal or imaging data after obvious clarification for the purpose as well as the anticipated scientific interests of the study. Moreover, the absolute confidentiality of the information was promoted.
The inclusion criteria for selection of the study sample were; Presence of all teeth in the region of measurements. Minimal or absent alveolar crest resorption in the examined regions. No artefacts in CBCT images. Exclusion criteria were; less than 10 years of age because of invisibility of mental foramen due to mixed dentition, distortion of images, Presence of artifacts, as well as nonvisualization of the mental foramen. The study materials were divided into three sets of less than 25 years (42 patient), 25 - 50 years (33 patient) and above 50 years (25 patient).

The cone beam images were imported to the Simplant program Ver. 17.01 (Dentsply Implants 3500 Hasselt Belgium). The 3D view was selected and magnified using the Zoom" tool then the "Measure distance" tool was selected from the tools menu. As previous studies demonstrated that, the mental foramens had almost symmetrical position on both sides (Junior et al. 2009 and Afkhami et al., 2013), the next measurements were taken on the right side of the mandible in actual 1:1 size in millimeters without magnification. (Figures 1)

A: Mandibular height, the distance from the inferior border of the mandibular body to the highest point of the alveolar crest (IBMHAC).

$\mathrm{B}$ : The distance between the inferior margins of the mental foramen to the inferior border of mandibular body. (IMMF-IBM)

$\mathrm{C}$ : The distance between the superior margins of the mental foramen to the highest point of the alveolar crest (SMMF-HAC).

$\mathrm{D}$ : The distance between the superior margins of the mental foramen to the inferior border of the mandible (SMMF-IBM).

E: Volume of mental foramen (VMF): The bone graft tool was selected and activated to fill the empty space of the mental foramen, and then the graft volume was converted into three-dimensional object. More clarification of the three- dimensional object was done by selecting the properties option from the panel to display the width, height, and depth of the mental foramen in millimeters and the volume in cubic centimeters in the second panel (figures 2). 


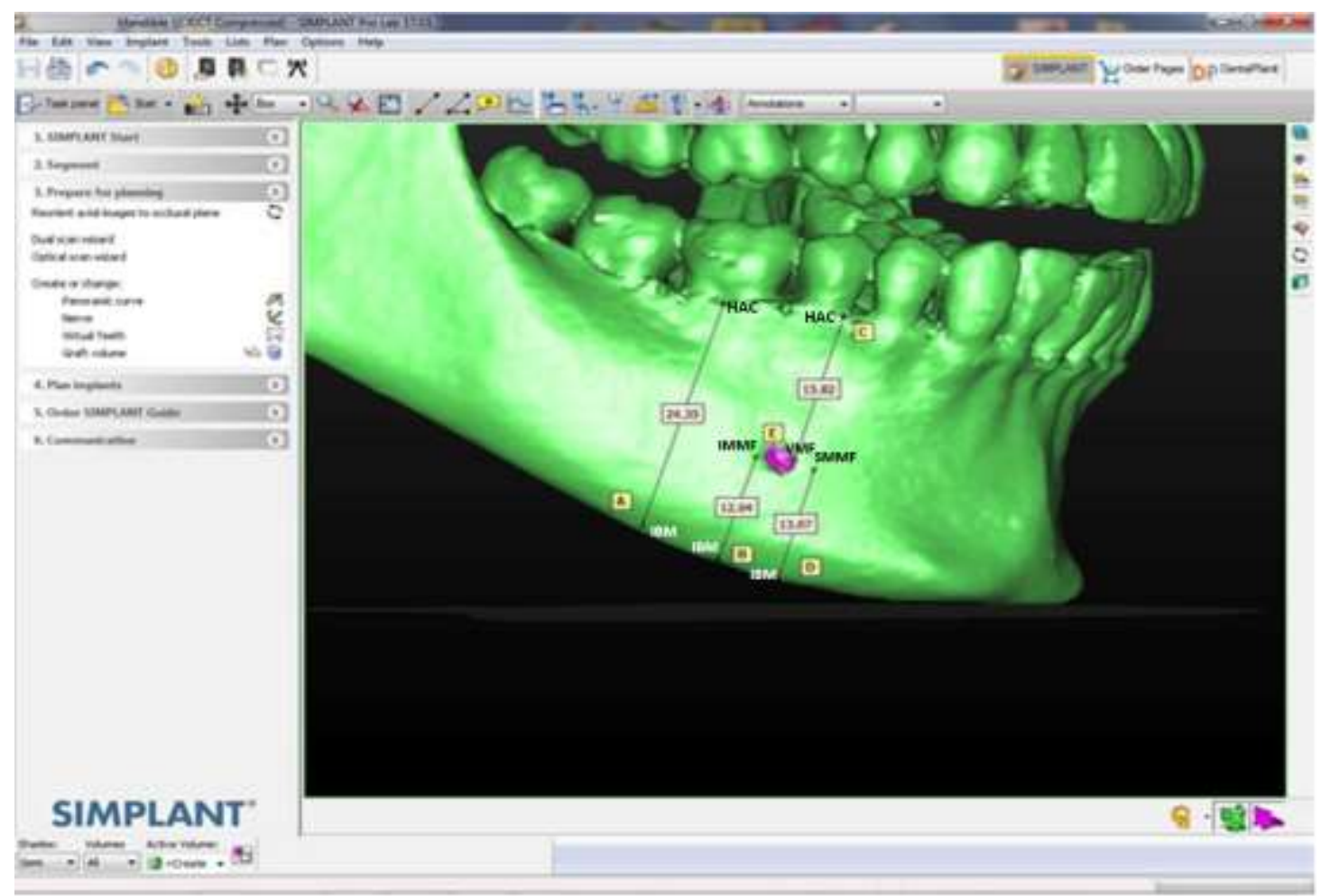

Figure (1): Cone beam image showing the measurements related right mandibular side; A :( IBM-HAC): Mandibular height, the distance from the inferior border of the mandibular body to the highest point of the alveolar crest. B :( IMMF-IBM): The distance between the inferior margins of the mental foramen to the inferior border of mandibular body. C: (SMMF-HAC): The distance between the superior margins of the mental foramen to the highest point of the alveolar crest. D: (SMMF-IBM): The distance between the superior margins of the mental foramen to the inferior border of the mandible. E: (VMF): Volume of mental foramen.

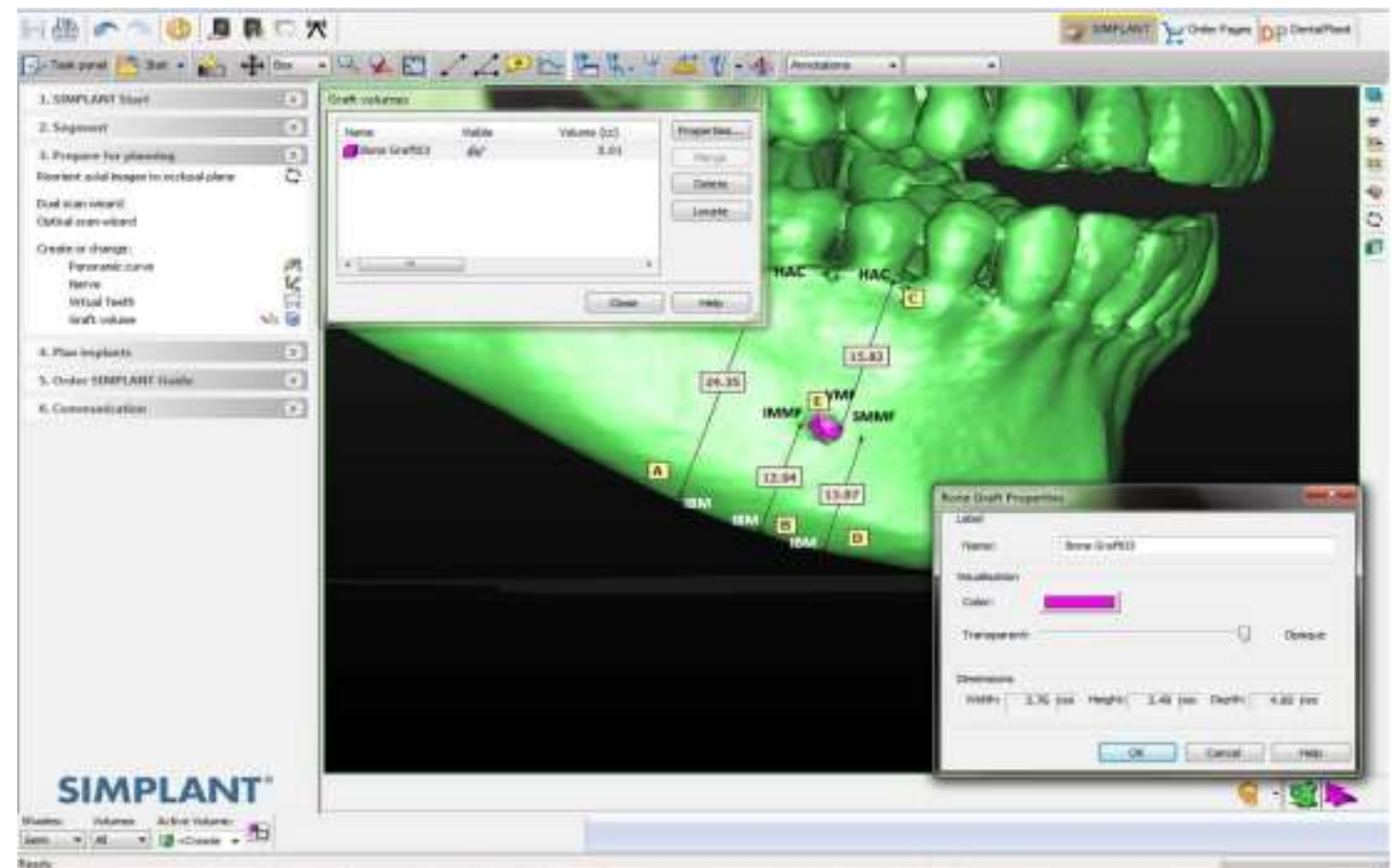

Figure (2): Cone beam image showing the measurements related right mandibular side; A :( IBM-HAC): Mandibular height, the distance from the inferior border of the mandibular body to the highest point of the alveolar crest. B :( IMMF-IBM): The distance between the inferior margins of the mental foramen to the inferior border of mandibular body. C: (SMMF-HAC): The distance between the superior margins of the mental foramen to the highest point of the alveolar crest. D: (SMMF-IBM): The distance between the superior margins of the mental foramen to the inferior border of the mandible. E: (VMF): Volume of mental foramen, employing the bone graft tool from Simplant program Ver. 17.01. 


\section{Statistical analysis:}

Data analysis was carried out using IBM SPSS statistics version 22. Numerical variables were checked for normality by Shapiro-Wilk test. All numerical variables were found to follow a normal distribution; therefore, values were summarized as mean \pm standard deviation and Independent-samples $\mathrm{T}$ test was implemented for comparison between men and women. For qualitative data, Pearson's Chi -square test was employed to examine the association among sex and age groups. Multiple regression analysis was done to examine the effect of predictors (age and sex) on the outcome (mandibular measurements). Forward stepwise binary logistic regression was carried out to foretell the probability of identifying male based on one or more independent variables (age and mandibular measurements). Significance was considered at $\mathrm{p}<0.05$ for interpretation of results of tests (William et al., 2015).

\section{III- RESULTS}

The distribution of age and sex of the study participants is depicted in figure (3) showing that the percentage of men was slightly higher than the women in all age groups, with no statistical significance ( $\mathrm{p}>$ 0.05). Table (1) compares the five studied measurements between the male and female participants. Men had a significantly higher mean mandibular height (IBM-HAC), SMMF-IBM, and VMF, than women ( $\mathrm{p}<$ 0.001). On the contrary, there was no significant difference between the means of IMMF-IBM and SMMF-HAC of men and women.

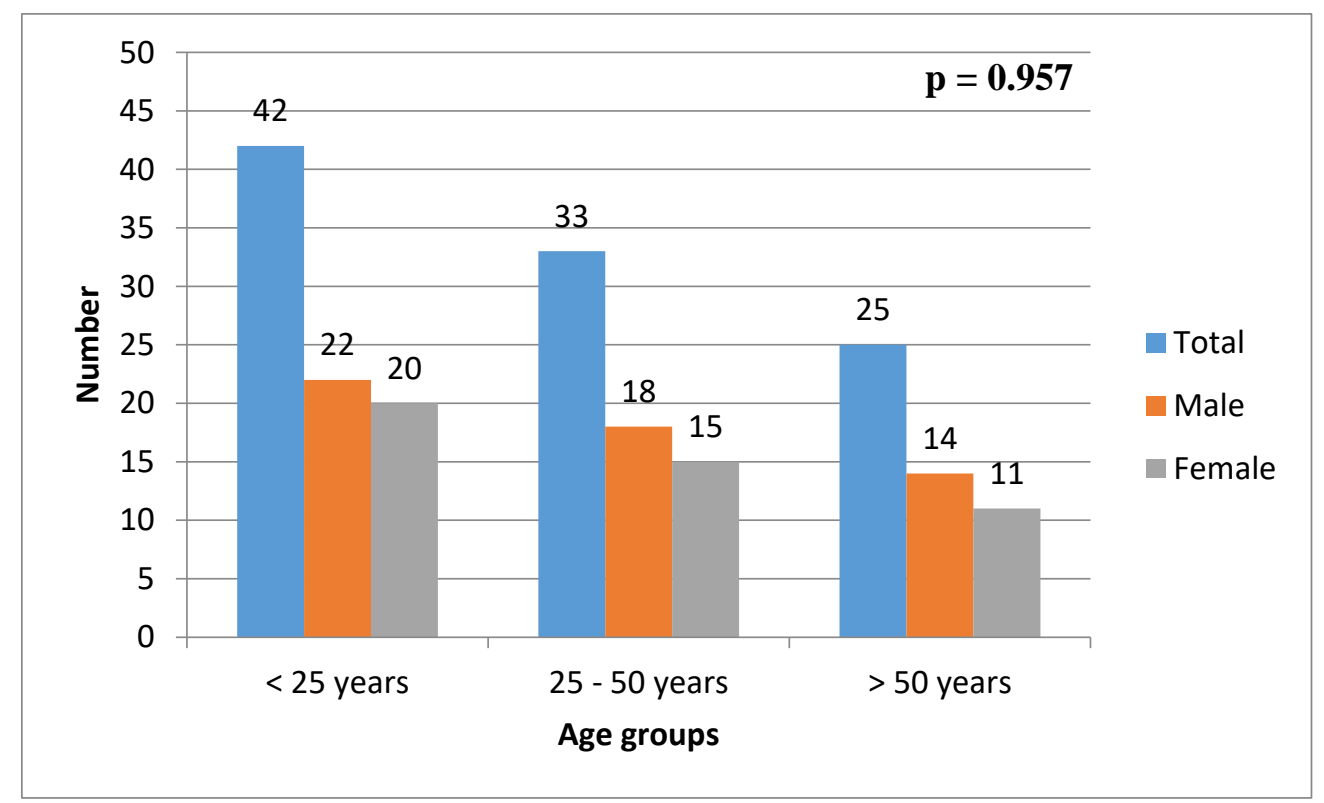

Figure (3): Bar chart showing distribution of age and sex in the study participants $(n=100 ; 54$ males \& 46 females) 
Table (1): Statistical comparison of the studied measurements between men and women in the different age groups by Student's -Test

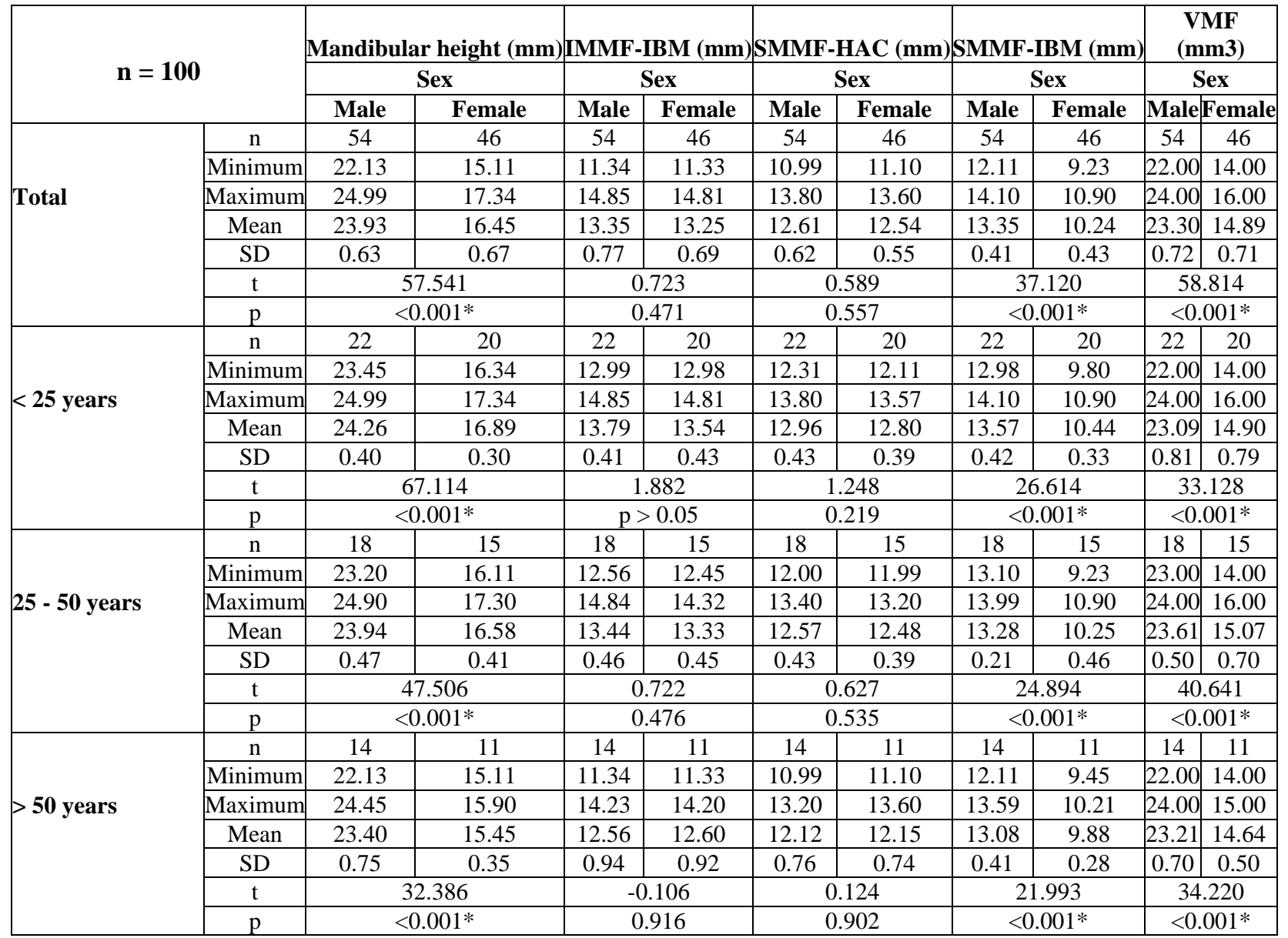

IMMF: Inferior margin of mental foramen; IBM: Inferior border of mandible; SMMF: Superior margin of mental foramen; HAC: Highest point of alveolar crest; VMF: Volume of mental foramen; $n$ : Number of patients $=100$ (54 males\&46 females); SD: Standard Deviation; t: Student's T- test; * significant at $\mathrm{p}<0.05 . ;$ highly significant at $\mathrm{p}<0.001$; NS=Non-significant $(\mathrm{p}>0.05)$.

The differences in mean mandibular height (IBM-HAC) between men and women, also between the three age groups showed slight decrease with increase of age, with the highest mean value at the age group "less than 25 years" (24.99 and $16.89 \mathrm{~mm}$ in male and female, respectively). This difference reached the lowest value in age group "above 50 years" (23.40 and $15.45 \mathrm{~mm}$ of male and female, respectively). Similar changes were noticed with mean value of SMMF-IBM, which was 13.57 and 10.44 in male and female participants aged less than 25 years; then reached 13.08 and 9.88 in male and female who were above 50 years. However, the mean VMF was slightly higher in both male and female participants who aged 25 to 50 years than those aged less than 25 or above 50 years old. (Figures 4-6). 


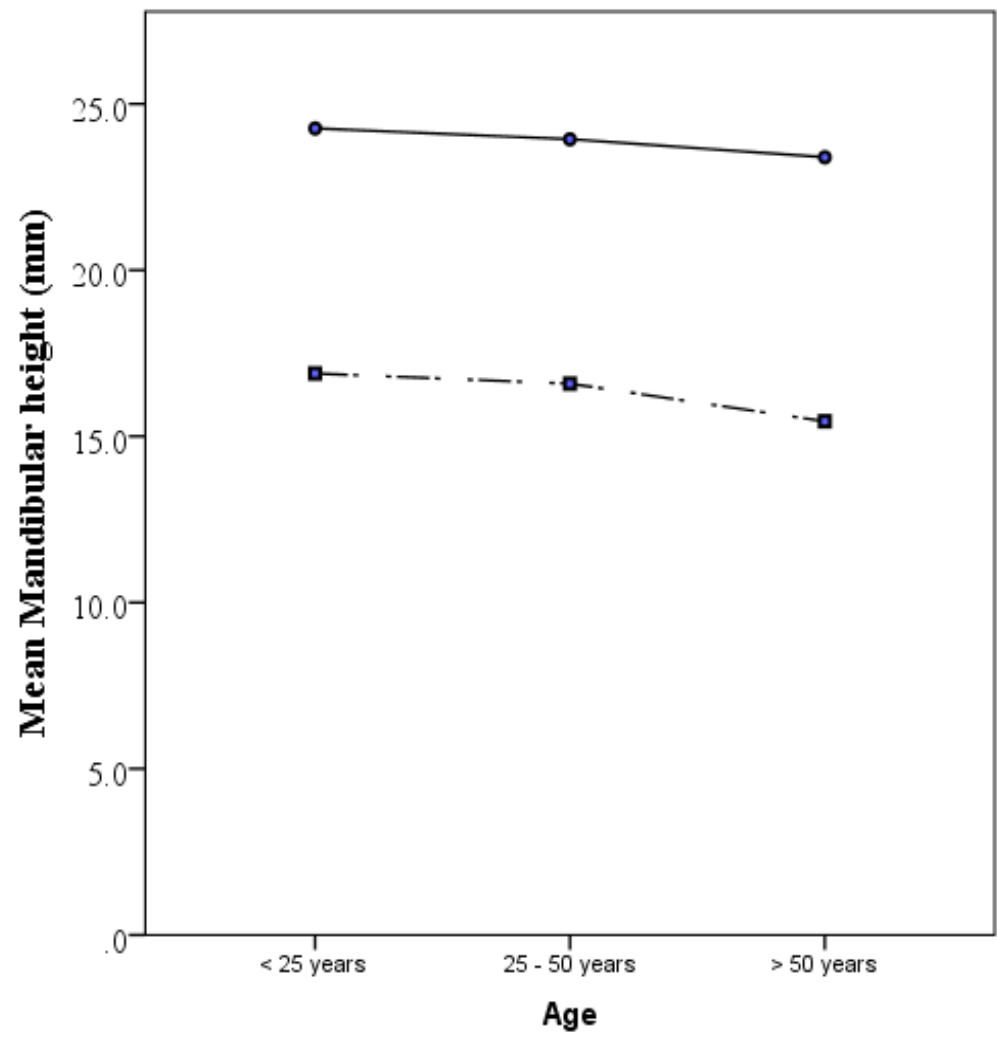

Figure (4): Comparison of mean mandibular height in men (continuous line) and women (interrupted line) among the three age groups

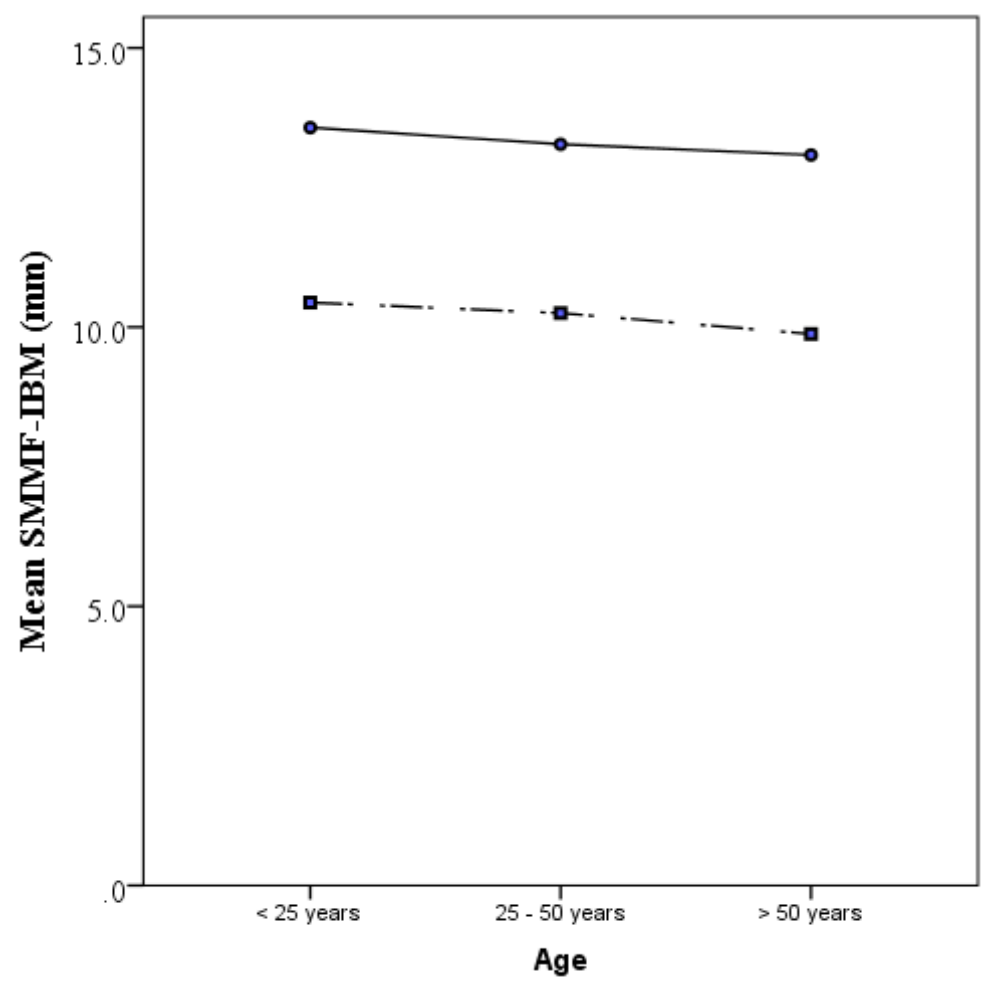

Figure (5): Comparison of mean superior margin of mental foramen - inferior border of mandible (SMMF-IBM) in men (continuous line) and women (interrupted line) among the three age groups. 


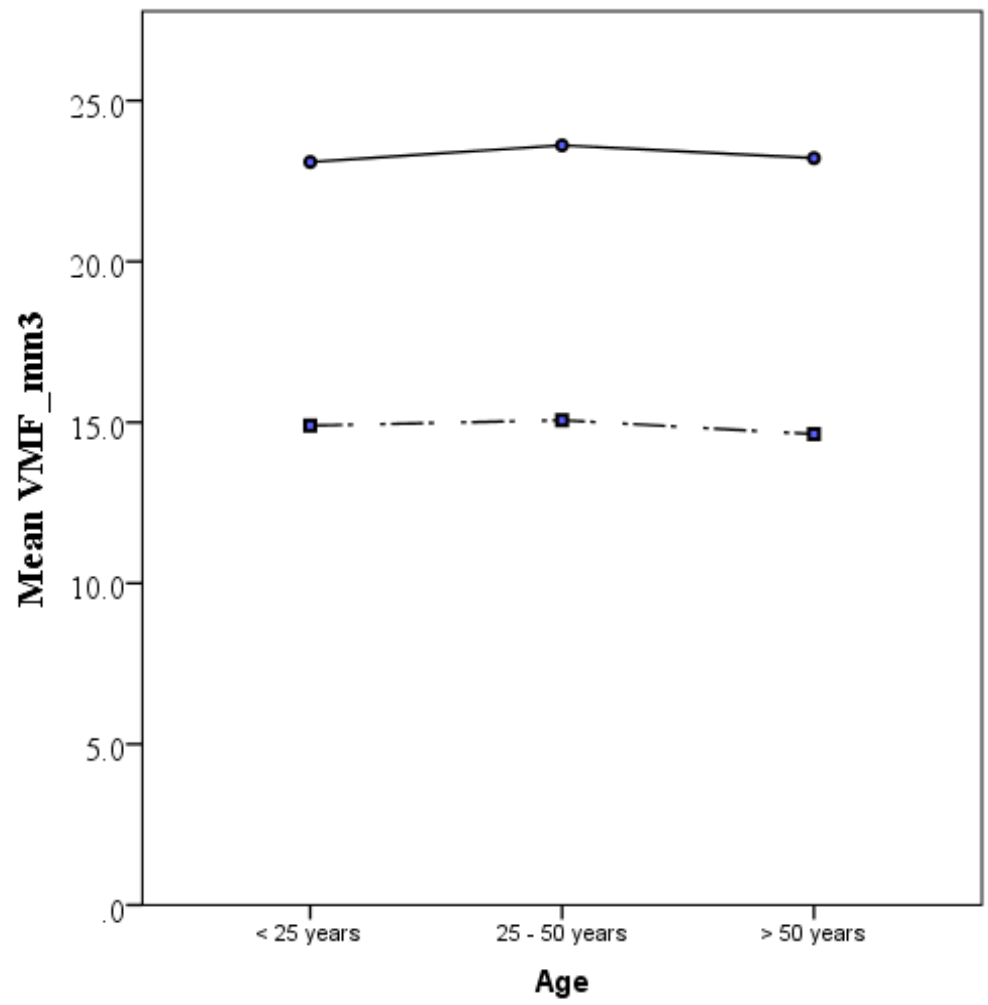

Figure (6): Comparison of mean volume of mental foramen (VMF) in men (continuous line) and women (interrupted line) among the three age groups.

Employing a multiple regression analysis to evaluate the effect of sex and age on the five studied measurements revealed that, increase in age was found to be significantly associated with a decrease in mandibular height (IBM-HAC), IMMF-IBM and SMMF-HAC, and SMMF-IBM (p $<0.001$, when adjusted for sex). However, increased age was not associated with a significant change in VMF ( $\mathrm{p}>0.05$, when adjusted for sex). Studying the effect of sex on the mandibular measurements revealed a significant effect on mandibular height (IBMHAC), SMMF-IBM, and VMF ( $p<0.001$, when adjusted for age). Sex was not associated with significant changes in IMMFIBM and SMMF-HAC ( $\mathrm{p}=0.279$ and 0.393 respectively, when adjusted for age), (table 2 ).

Table (2): Multiple regression analysis to evaluate the effect of sex and age on the five studied measurements:

\begin{tabular}{|c|c|c|c|c|c|c|c|}
\hline \multirow{2}{*}{\multicolumn{2}{|c|}{ Model }} & \multicolumn{2}{|c|}{$\begin{array}{c}\text { Unstandardized } \\
\text { Coefficients }\end{array}$} & \multirow[t]{2}{*}{$\mathbf{t}$} & \multirow[t]{2}{*}{$\mathbf{p}$} & \multicolumn{2}{|c|}{$95.0 \%$ CI for B } \\
\hline & & B & Std. Error & & & Lower Bound & Upper Bound \\
\hline Mandibular height (mm & Age & -0.540 & 0.060 & -8.975 & $<0.001 *$ & -0.660 & -0.421 \\
\hline & Sex & -7.510 & 0.097 & -77.683 & $<0.001 *$ & -7.702 & -7.318 \\
\hline IMMF-IBM (mm) & $\begin{array}{l}\text { Age } \\
\text { Sex }\end{array}$ & $\begin{array}{l}-0.527 \\
-0.132 \\
\end{array}$ & $\begin{array}{l}0.075 \\
0.121 \\
\end{array}$ & $\begin{array}{l}-6.995 \\
-1.089 \\
\end{array}$ & $\begin{array}{c}<0.001^{*} \\
0.279 \\
\end{array}$ & $\begin{array}{l}-0.676 \\
-0.372 \\
\end{array}$ & $\begin{array}{c}-0.377 \\
0.108 \\
\end{array}$ \\
\hline SMMF-HAC (mm) & $\begin{array}{l}\text { Age } \\
\text { Sex } \\
\end{array}$ & $\begin{array}{l}-0.376 \\
-0.088 \\
\end{array}$ & $\begin{array}{l}0.064 \\
0.102 \\
\end{array}$ & $\begin{array}{l}-5.913 \\
-.858 \\
\end{array}$ & $\begin{array}{c}<0.001 * \\
0.393\end{array}$ & $\begin{array}{l}-0.502 \\
-0.290 \\
\end{array}$ & $\begin{array}{c}-0.249 \\
0.115 \\
\end{array}$ \\
\hline SMMF-IBM (mm) & $\begin{array}{l}\text { Age } \\
\text { Sex }\end{array}$ & $\begin{array}{l}-0.260 \\
-3.116 \\
\end{array}$ & $\begin{array}{l}0.045 \\
0.073\end{array}$ & $\begin{array}{c}-5.749 \\
-42.913 \\
\end{array}$ & $\begin{array}{l}<0.001 * \\
<0.001 *\end{array}$ & $\begin{array}{l}-0.350 \\
-3.260 \\
\end{array}$ & $\begin{array}{l}-0.170 \\
-2.972 \\
\end{array}$ \\
\hline VMF (mm3) & $\begin{array}{l}\text { Age } \\
\text { Sex }\end{array}$ & $\begin{array}{c}0.006 \\
-8.405 \\
\end{array}$ & $\begin{array}{l}0.089 \\
0.144\end{array}$ & $\begin{array}{c}0.068 \\
-58.487\end{array}$ & $\begin{array}{c}0.946 \\
<0.001 *\end{array}$ & $\begin{array}{l}-0.171 \\
-8.690 \\
\end{array}$ & $\begin{array}{c}0.184 \\
-8.119 \\
\end{array}$ \\
\hline
\end{tabular}

IMMF: Inferior margin of mental foramen; IBM: Inferior border of mandible; SMMF: Superior margin of mental foramen; HAC: Highest point of alveolar crest; VMF: Volume of mental foramen; B: Unstandardized coefficients; CI: Confidence Interval; $\mathrm{t}=\mathrm{t}$ test, * significant at $\mathrm{p}<0.05$. ${ }^{*}$ Highly significant at $\mathrm{p}<0.001$.

The results of a forward stepwise binary logistic regression predicting sex were illustrated in (table 3). The measurements included in the analysis were those significantly different between the male and female participants. After carrying out the 
logistic regression for mandibular height (IBM-HAC), SMMF-IBM, and VMF, only SMMF-IBM, and VMF - in addition to age group - were significantly contributing to the regression model, while mandibular height (IBM-HAC) was excluded. The logistic regression model was statistically significant, $\chi^{2}=138.629, p<0.001$. The model clarified $75 \%$ (Cox \& Snell $R^{2}$ ) of the difference in sex and accurately categorized all cases. Based on the logistic regression model, an equation for prediction of sex was derived:

Logit $(\mathrm{p})=-143.56+(5.17 \times$ SMMF- IBM $)+$ $(4168.1 \times \mathrm{VMF})+(1.547 \times$ age $)$

Where age is coded as 1 if less than 25; 2 if between 25 and 50; and 3 if above 50 years.

Logit (p) can be transformed into $\mathrm{P}$ (probability of being male) by the following formula: $p=\frac{1}{1+\mathrm{e}^{-\operatorname{logit}(\mathrm{p})}}$

Table (3): Forward stepwise binary logistic regression predicting sex based on the studied measurements:

\begin{tabular}{|c|c|c|c|c|c|c|}
\hline \multicolumn{2}{|c|}{ Chi square test } & \multirow[b]{2}{*}{$\begin{array}{c}\text { Cox \& Snell } \\
\text { R Square }\end{array}$} & \multirow{2}{*}{$\begin{array}{l}\text { Percentage } \\
\text { accuracy in } \\
\text { classification }\end{array}$} & \multirow[t]{2}{*}{ Variables } & \multicolumn{2}{|c|}{ Coefficients } \\
\hline $\mathrm{X}^{2}$ & $\mathrm{p}$ & & & & B & $\begin{array}{c}\operatorname{Exp}(\mathrm{B}) \\
\text { (Odds ratio) }\end{array}$ \\
\hline \multirow{4}{*}{138.629} & \multirow{4}{*}{$<0.001 *$} & \multirow{4}{*}{0.750} & \multirow{4}{*}{$100.0 \%$} & Age & 1.547 & 4.698 \\
\hline & & & & SMMF- IBM & 5.172 & 176.262 \\
\hline & & & & VMF & 4168.097 & \\
\hline & & & & Constant & -143.562 & 0.000 \\
\hline
\end{tabular}

IBM: Inferior border of mandible; SMMF: Superior margin of mental foramen; VMF: Volume of mental foramen. $\mathrm{X}^{2} \mathrm{Chi}$ square test; Cox \& Snell R Square.

\section{IV- DISCUSSION}

In the present work, men had significantly higher mean mandibular height (IBM-HAC), than women ( $\mathrm{p}<0.001)$. These differences were observed when studying the total study sample, as well as in all age groups and these results were in accordance with other studies conducted on dentulous and edentulous persons that concluded the significantly greater maxillary and mandibular measurements in men than women. (Ortman et al., 1989; De Baat et al., 1993 and Moni et al., 2014).

As proved in this research, the mean values of SMMF-IBM were significantly higher in males than females in all age groups. Previous studies on other races reported similar results (Mahima et al., 2009) and (Chandra et al.,2013) in India, (Afkhami et al., 2013) in Iran, (Catovie et al., 2002) in Croatia, (Thomas et al., 2004) in Australia, and (EL gazzar et al., 2012) in Egypt. Also in this study, the mean values of IMMF-IBM and SMMF-IBM in both sexes were smaller than reported in previous Indian studies (Rajani and Srivastav 2010 \&Sankar et al., 2011).
As illustrated in the current results, Men had significantly higher mean VMF than women $(p<0.001)$. This goes in accordance with a previously published report for studying the average sizes of long and short axes of mental foramina of both sexes using dried adult human mandibles (Rajani and Srivastav 2010). On the other hand, another study from Sri Lanka denied any significant difference in shape and position of the mental foramina in both sexes (Prabodha and Nanayakkara 2006).

In our existing study, the mean VMF was slightly higher in both male and female participants who aged 25 to 50 years than those aged less than 25 years old. This could be explained by the various changes occurring in bone with age in the form of obvious raise in cortical porousness and increase resorption rate of canals of Havers (Vodanovic et al., 2006; Ngeow et al., 2010 and Mahnaz \& Mitra, 2016). 
Our results demonstrate that there was no considerable difference among the means of IMMF-IBM and SMMF-HAC of men and women and these results go hand in hand with: Indian study (Moni et al., 2014), and Iranian study (Haraji and Boostani,2013). On the contrary, other studies from Egypt (EL gazzar et al., 2016), India (Sankar et al, 2011), and Brazil (Amorim et al, 2008) proved a significant difference among the means of IMMF-IBM and SMMF-HAC. These observed differences may be attributed to different methodology such as measurements on dry skull, photographs or radiographs (YiPing et al., 2010).

In this work, Increase in age was found to be significantly associated with a decrease in the studied mandibular measurements when adjusted for sex. These results coincide with those of Singleton et al. (2006) and Yi-Ping et al. (2010), who stated that the decrease of the height of mandibular residual ridge correlates with the decrease of the mandibular bone density and the age. Also with Jonasson and Rythén, (2016), who reported a significant high difference between males and females in midline and mental foramen areas. In addition, Franklin et al., (2008), in their study on South Africans Population, concluded about the continuous reduction in bone height with age due to multiple systemic and local factors, this reduction is greater in females.

The significant influence of sex on the analyzed measurements with the higher values observed in males may be attributed to the higher rate of bone growth of craniofacial dimensions in males under effects of sex hormones. In addition, There is considerable differences in mental foramen position between the two sexes (Rashid and Ali, 2011; Lubis and Anfelia, 2018 and Naveen et al., 2018). Moreover, mandibular dimorphism is influenced by the strength of mastication muscles (Humphrey et al., 1999; Greenstein and Tarnow, 2006).

The measurements obtained from the current study were more comparable to those of direct measurement investigated by Apinhasmit et al., (2006) on 106 Thai adult skulls. In addition, many investigators had reported the results of CT scans as more precise than plain radiographs to reveal mental foramen (Ngeow et al., 2010\& Alessandro et al., 2017). According to Alessandro et al., (2017), digital distances taken on CBCT images may conduct dependable results when compared to measurements gained through a digital caliper.

\section{V- CONCLUSION}

From the five studied measurements, men had significantly higher mean mandibular height (IBM-HAC), SMMF-IBM, and VMF, than women. Contrariwise, there was no significant difference between the means of IMMF-IBM and SMMF-HAC of men and women. Logistic regression revealed SMMF-IBM, and VMF, in addition to age group, as significant contributors to the regression model. The logistic regression model was statistically significant to clarify $75 \%$ of sex difference with an accurate categorization of all cases. Based on the logistic regression model, an equation for prediction of sex was created that could be used for prediction of sex in forensic odontology.

\section{VI- RECOMMENDATIONS}

It is a scientific request to expand the study of forensic odontology in Arabic countries and to provide the scientific fields for training among different sectors of the forensic professionals. The advantages of CBCT in the field of forensic odontology should be highlighted in both forensic and police circles. Conducting further inclusive studies on larger scales may improve the accuracy of the results. In addition, Studies considering group specific standards are increasingly asked as the surrounding environment and occupation may affect the skeleton and subsequently bones measurements.

\section{Acknowledgment}

The authors are very grateful to all patients who participate in this study. A warm expression of thanks is due to the administrative and medical affairs of the involved dental care academies.

\section{Disclosure statement}

There are no conflicts of interest. 


\section{VII- REFERENCES}

Afkhami F., Haraji A., and Boostani H.R. (2013): Radiographic localization of the mental foramen and mandibular canal. J Dent (Tehran), 10(5): 436.

Akhilesh C., Anil S., Manjunath B., Rohit J., and Archana A. (2013): Determination of sex by radiographic analysis of mental foramen in North Indian Population. Journal of Forensic Dental Sciences, 5(1): 52-55.

Alessandro A.L., Ademir F., Angela F., Claudio J.S., Barbos A., and Fernando H. (2017): Accuracy of linear measurements performed with two imaging software in cone-beam computed tomography scans of dry human mandibles. An Acad Bras Cienc, 89(4): 2865-2873.

Amorim M.M., Prado F.B., and Borini C.B. (2008): The mental foramen in dentate and edentulous Brazilian's mandible. Int. J. Morphol, 26(4): 981-987.

Annamalai P.I., Archana M., and Maria P.D. (2012): Mandibular ramus: An indicator for sex determination - A digital radiographic study. Journal of Forensic Dental Sciences, 4(2): 58-62.

Apinhasmit W., Chompoopong S., Methathrathip D., Sansuk R. and Phetphunphiphat W. (2006): Supraorbital Notch/Foramen, infraorbital foramen and mental foramen in Thais: anthropometric measurements and surgical relevance. Journal of the Medical Association of Thailand, 89(5): 675-682.

Cagri U., Cihan B., Ismail S., Ali M., and Yusuf Z. (2011): Bone height measurement of maxillary and mandibular bones in panoramic radiographs of edentulous patients. J Clinc. Exp Dent, 3(1): 5-9.

Catovie A., Bergman V., and Seifert D. (2002): Influence of sex, age and presence of functional units on optical density and bone height of the mandible in the elderly. Acta Stomatol Croat, 6: 327-328.

Chandra A., Singh A., and Badni $M$. (2013): Determination of sex by radiographic analysis of mental foramen in North Indian population. Forensic Dent Sci., 5(1): 52- 55.

De Baat C., Kalk W., and Vant H. (1993): Factors connected with alveolar bone resorption among instutionalized elderly people. Community Dent Oral Epidemiol, 21: 317-325.

EL Gazzar F.M., El - Sarnagawy G.N. and EL-Gendy A.R. (2016): SEXUAL DIMORPHISM OF THE MANDIBLE IN EGYPTIAN POPULATION SAMPLE: A PANORAMIC RADIOGRAPHIC STUDY. Egypt. J. Forensic Sci.Appli. Toxicol, 16(2): 127- 137.

Franklin D., O'Higgins P., Oxnard C.E., and Dadour I. (2008): Discriminant function sexing of the mandible of Indigenous South Africans. Forensic Sci Int, 179: 84e1-84e5. doi:10.1016/j.forsciint.2008.03.014

Greenstein G. and Tarnow D. (2006): The mental foramen and nerve: clinical and anatomical factors related to dental implant placement: a literature review. Journal of Periodontology, 77(12): 1933-1943.

Haraji F.A. and Boostani H.R. (2013): Radiographic localization of the mental foramen and mandibular canal. J Dent (Tehran), 10(5): 436- 442.

Humphrey L.T., Dean M.C., and Stringer C.B. (1999): Morphological variation in great ape and modern human mandibles. J Anat, 195: 491-513.

Jonasson R. and Rythén M. (2016): alveolar bone loss in osteoporosis: a loaded and cellular affair? Clinical cosmetic and investigation dentistry, 8: 95-103.

Junior O.E.M., Araujo A.L.D., Da Silva C.M.F, Sousa C.F., and Lima F.J. (2009): Morphological and morphometric study of the mental foramen on the M-CP-18 jiachenjiang point. Int. J. Morphol., 27(1): 231-8.

Lubis M.N and Anfelia G. (2018): Vertical Height and Horizontal Width Assessment of Mental Foramen for Sex Determination from Panoramic Radiograph.EC Dental Science, 17(2): 34-38.

Mahima V.G., Patil K., and Srikanth H.S. (2009): Mental foramen for gender determination: A panoramic radiographic study. Medico-Legal Update, 9: 33-37

Mahnaz S. and Mitra K.K. (2016): CBCT Assessment of Mental Foramen Position Relative to Anatomical Landmarks. International Journal of Dentistry, 3: e1- e4. doi.org/10.1155/2016/5821048 
Moni T. Reddy K. V., Sivaranjani Y, and Shaikh K. (2014): Gender Determination by Mental Foramen and Height of the Body of the Mandible in Dentulous Patients: A Radiographic Study Indian Acad Forensic Med, 36(1): 13-18.

Naroor N., Shenai P., Chatra L., and Vena K.M. (2015): Gender determination using the mental foramen. J Cranio Max Dis, 4 (2):144147.

Naveen S., Ketkis., and Sneha K.(2018): Mental formen in Sex Determination.Acta Scientific Dental Science, 2(5): 40-43.

Ngeow W.C.,Dionyins D.D.,Ishak H.,and Nambiar P.(2010): Aging Towards Location and Visibility of Mental Foramen on Panoramic Radiographs.Singapore Dental Journal, 31(1): 15-19.

Ortman L.F., Hausmann E., and Dunford R.G. (1989): Skeletal osteopenia and residual ridge resorption.J Prosthet Dent, 61: 321-325.

Prabodha L.B. and Nanayakkara B.G. (2006): The position, dimensions and morphological variations of mental foramen in mandibles. Galle Medical Journal, 11(1): 13-15.

Rajani S. and Srivastav A. K. (2010): Study of Position, Shape, Size and Incidence of Mental Foramen and Accessory Mental Foramen in Indian Adult Human Skulls.Int.J.Morph, 28(4): 1141-1146.

Rashid S.A. and Ali J. (2011): Sex determination using linear measurements related to the mental and mandibular foramina vertical positions on digital panoramic images. J Bagh College Dentistry, 23: 59-64.

Sankar D.K., Bhanu S.P, and Susan P.J. (2011): Morphometrical and morphological study of mental foramen in dry dentulous mandibles of South Andhra population of India. J Dent Res. 22(4): 542-546.

Singleton D.A., Buschang P.H., Behrents R.G., and Hinton R.J. (2006): Craniofacial growth in growth hormone-deficient rats after growth hormone supplementation. Am J Orthod Dentofacial Orthop., 130: 69-82.

Thiago O.G, Marcelo C.A, and Francisco H.N. (2016): Mandibular sexual dimorphism analysis in CBCT scans. Journal of Forensic and Legal Medicine, 38: 106-110.

Thomas C.J., Madsen D., and Whittle C. (2004): A radiologic survey of the edentulous mandible relevant to forensic dentistry. Leb $\mathrm{J}$ Dent Med, 3: 15-20.

Vodanovic M., Dumancic J., Demo Z., and Mihelic D. (2006): Determination of sex by discriminant functional analysis of mandibles from two Croatian archeological sites. Acta Stomatol Croat, 40: 263-377.

Wei C.N., Dionetta D.D., Hayati L., and Phrabhakaran N. (2010): Effect of Ageing Towards Location and Visibility of Mental Foramen on Panoramic Radiographs. Singapore Dental Journal, 31(1): 15-19.

William D., Robbi A., Jeffery H., Callie M. and Jacob E. (2015): Use of Pearson's Chisquare for Testing Equality of Percentile profiles Across Multiple Populations. Open J Stat, 5(5): 412-420.

Yi-Ping, Behrents R. G. and, Buschang P.H. (2010): Mandibular Growth, Remodeling, and Maturation During Infancy and Early Childhood. Angle Orthodontist, 80(1): 97-105. 
التنبؤ بالجنس باستخدام قياسات الفك السفلي: استخدام الأشعة المقطعية المخروطية

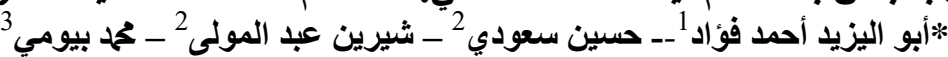

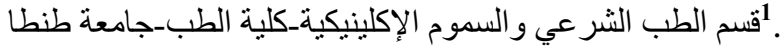

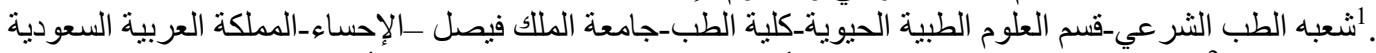

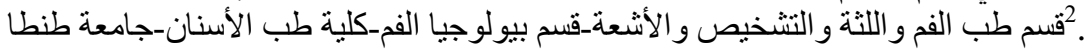

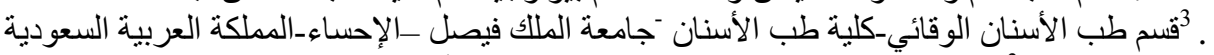

3قنسم الدراسات العليا-جامعة بار اجو اي المستقلة_أسونشيان -بار اجواي.

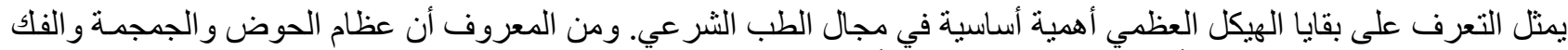

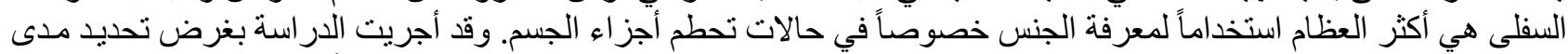

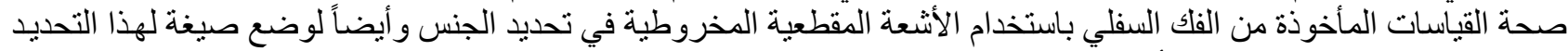

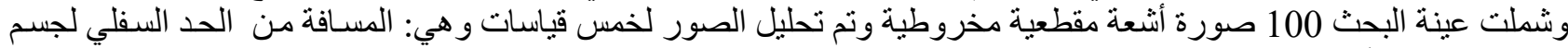

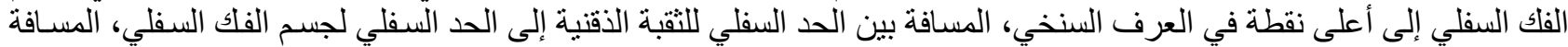

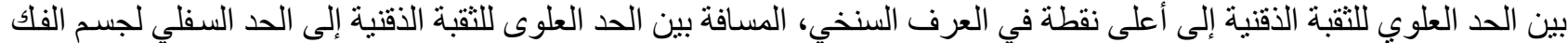

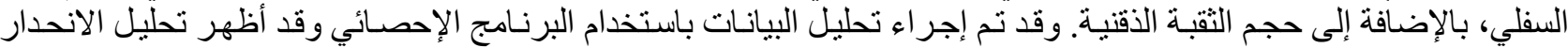

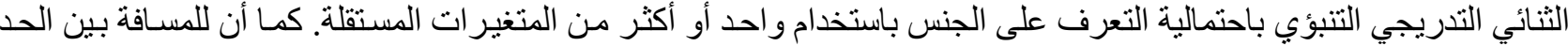

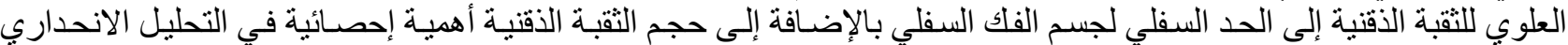

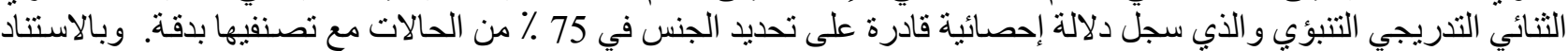

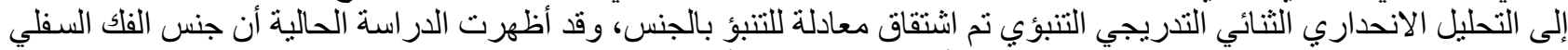

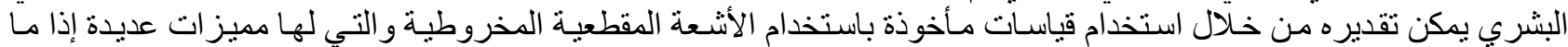
قورنت بتقنيات الأشعة الأخرى. 